\title{
Thermally induced icequakes detected on blue ice areas of the East Antarctic ice sheet
}

\author{
Denis LOMBARDI, ${ }^{1}$ Irina GORODETSKAYA, ${ }^{2}$ Guilhem BARRUOL, ${ }^{1}$ c] \\ Thierry CAMELBEECK ${ }^{3}$ \\ ${ }^{1}$ Université de Paris, Institut de physique du globe de Paris, CNRS, F-75005 Paris, France. \\ E-mail: lombardi.geoscope@gmail.com \\ ${ }^{2}$ CESAM - Centre for Environmental and Marine Studies, Department of Physics, University of Aveiro, Aveiro, Portugal \\ ${ }^{3}$ Royal Observatory of Belgium, Avenue Circulaire 3, B-1180, Uccle, Brussels, Belgium
}

\begin{abstract}
Over a year of seismic observations, 5000 short duration icequakes were detected by a permanent broadband station installed at the Princess Elisabeth base, located $\sim 180 \mathrm{~km}$ inland in eastern Dronning Maud Land, East-Antarctica. Icequake detection via seismic waveform pattern recognition indicates the presence of two dominating clusters of events, totalizing $\sim 1500$ icequakes. The corresponding icequake locations point towards two distinct zones of outcropping blue ice areas (BIAs) located respectively at 4 and $\mathbf{1} \mathrm{km}$ from the seismic station, both on the leeward side of a nunatak protruding through the ice sheet. The temporal occurrence of these icequakes suggests a close genetic link with thermal contraction of ice caused by significant surface cooling controlled, in summer by variations in diurnal solar radiation and in winter by strong cooling during cold katabatic regimes. Further analysis demonstrates the dependence of these icequakes on the absolute surface temperature and on its temporal change. Besides providing information on the ice fracture mechanics and rheology, investigations of thermal icequakes may be regarded as a ground-based proxy for the monitoring of the thermal state of BIAs, and characterization of ice-sheet ablation zones.
\end{abstract}

KEYWORDS: Antarctic glaciology, blue ice, ice rheology, ice temperature, seismology

\section{INTRODUCTION}

In the recent years, the growing interest in understanding rapid changes in the cryosphere dynamics has promoted passive seismology as a major tool in the field of glaciology (Podolskiy and Walter, 2016; Aster and Winberry, 2017). The most common type of observed seismicity is the one generated by ice surface cracking and crevassing, generating the so-called 'icequake' signals (Neave and Savage, 1970; Walter and others, 2009; Mikesell and others, 2012; Röösli and others, 2014). In Antarctica, the majority of these surface icequakes involves dynamic processes in extensional regime at the ice-sheet margin such as during ice shelf rifting (Bassis and others, 2007; Heeszel and others, 2014) or tideinduced bending (von der Osten-Woldenburg, 1990; Barruol and others, 2013; Lombardi and others, 2016). Surface cryo-seismicity induced by variations in thermal stress also exists but its investigation remains so far limited to few examples: on ice sheet (Nishio, 1983; Lough and others, 2015), on sea ice (Crary, 1955; Milne, 1972; Xie and Farmer, 1991; Lewis, 1994) and recently on temperate glaciers (Podolskiy and others, 2018) and on ice shelf (MacAyeal and others, 2018). Although thermally induced icequakes have small amplitudes and their penetration depths are likely very superficial (few $\mathrm{cm}$ to $1 \mathrm{~m}$ ), and thus do not present a direct threat for ice sheet or ice shelf stability, they may be of large interest for understanding ice and snow mechanics, and also to potentially monitor the thermal state of the ice sheet and its long-term variations. Thermal stress is a natural phenomenon that likely also affects, at longer timescales, the surface of the outer planet icy moons (e.g. Ferrari, 2018). Detailed investigations of such processes on Earth may, therefore, be of interest in the light of future space science missions that may envision seismic measurements (Panning and others, 2018; Vance and others, 2018).

To our knowledge, the works of Nishio (1983) and Lough and others (2015) are the only investigations of the thermal stress seismicity of the Antarctic ice sheet. The pioneering work of Nishio (1983) provided a very comprehensive insight into the occurrence of the so-called 'snowquakes' related to thermal stress during an 8-month period near the Mizuho base $\left(70^{\circ} 42^{\prime} \mathrm{S}, 44^{\circ} 20^{\prime} \mathrm{E}\right.$, a Japanese base presently abandoned) located on the edge of the Antarctic plateau at $2230 \mathrm{~m}$ a.s.l. The author showed that the snowquakes preferentially develop in two situations: during summer at night time when snow temperature decreases when incoming solar radiation is minimum and during winter associated with inland high-pressure atmospheric system. He attributed those events to snow thermal contraction associated with the formation of few-cm-wide thermal cracks penetrating the surface down to $\sim 1 \mathrm{~m}$. More recently, re-analyzing the TAMSEIS and GAMSEIS seismic dataset, Lough and others (2015) found 'firnquakes' detectable at distances as large as several hundreds of $\mathrm{km}$. They attributed these events to wind-glazed macrocracks formation in the firn layer. Despite the lack of information relative to temperature, the authors interpret these events as resulting from the cooling induced by persistent katabatic winds leading to firn thermal contraction.

The present paper aims at complementing those studies, providing local observations of thermal stress-induced seismicity over a whole year (February 2012 to January 2013) by using data recorded by permanent seismic and weather stations installed near the Princess Elisabeth Antarctica base $\left(71.94^{\circ} \mathrm{S}, 23.34^{\circ} \mathrm{E}\right.$, hereafter referred to as 'PEA'), located 
$\sim 180 \mathrm{~km}$ from the coast and $\sim 1400 \mathrm{~m}$ a.s.l. in the escarpment zone of the East Antarctic ice sheet.

\section{SEISMIC OBSERVATIONS}

\section{Detection of icequakes}

Since 2009, a seismic instrument has been operating near PEA, eastern Dronning Maud Land, East-Antarctica. It sits on a narrow, elongated granitic ridge as an extension of the imposing pyramid-shaped Utsteinen nunatak (Fig. 1) protruding $300 \mathrm{~m}$ above the surface of the ice sheet. The instrument is a broadband seismometer with a flat response within the 120 seconds to $100 \mathrm{~Hz}$ band, with 24-bit digitizer sampling at $100 \mathrm{~Hz}$. The proximity of PEA $(\sim 350 \mathrm{~m})$ provides an easy ground access and reliable power supply to the seismic station.

We investigated continuous seismic recordings of this permanent seismic station throughout the period February 2012 to January 2013, which is the longest available period of recordings with no data gaps. The data were bandpass filtered between 5 and $20 \mathrm{~Hz}$. Detection of short duration local events was performed using the conventional triggering technique based on the ratio of short-term average over longterm average (STA/LTA, Allen, 1978). Durations of 1.5 and 40 seconds were used for STA and LTA windows, respectively. A STA/LTA threshold of 20 and subsequent visual inspection allowed to detect more than 5000 seismic events. Visual inspection revealed a high degree of similarity between most of these events. We, therefore, decided to proceed using cross-correlation-based detection technique selecting, as master events, five waveform patterns with the largest amplitude and initially found via the STA/LTA detection technique. A 2-second long window on the vertical component was first used to detect similar seismic waveforms and subsequent correlation search was performed with the two horizontal components to accept seismic events meeting cross-correlation values higher than 0.50 . In total, 4200 events were extracted using this technique. To classify the icequakes and to provide clusters of events, a hierarchical clustering analysis was performed. The waveform cross-correlation value based on a 1 second window encompassing the surface wave arrivals was used to construct a correlation matrix for the entire event dataset.

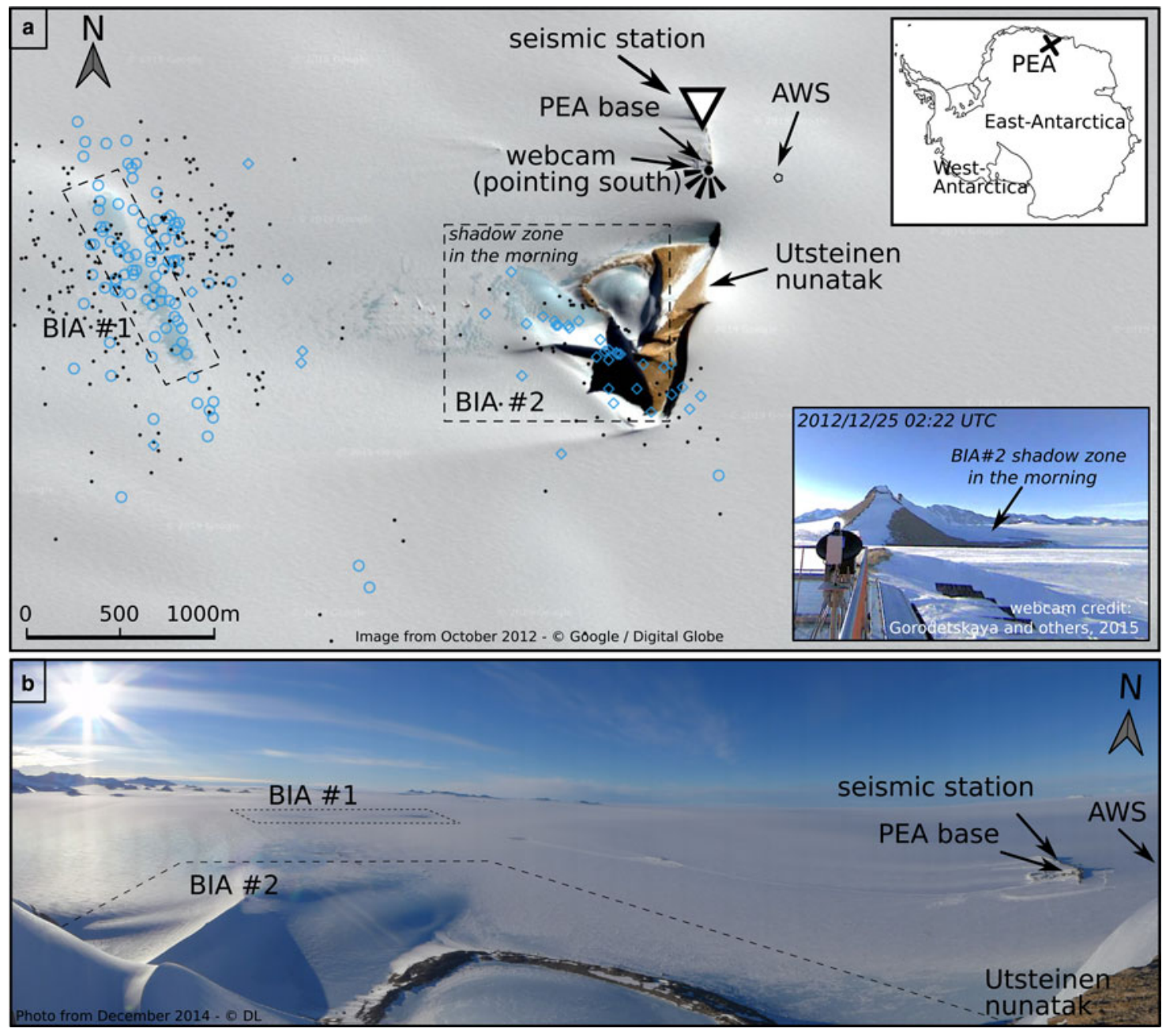

Fig. 1. Location map of the study area (a). The seismic station is marked with a white triangle. The automatic weather station (AWS) is indicated by an open hexagon. The locations of thermal icequakes are marked with open circles for cluster \#1 and open diamonds for cluster \#2. They are concentrated on the two BIAs marked by two dashed rectangles. The black dots illustrate the location variability using velocity ranges around the mean values (see text). The upper right inset shows the location of PEA base on the Antarctic continent. The lower right inset shows a webcam view from PEA towards the Utsteinen nunatak from 25 December 2012 at 02:22 UTC. In the morning (UTC time), the nunatak, protruding $300 \mathrm{~m}$ above the ice surface, creates a prominent shadow zone on its western flank where the BIA \#2 is located. The photograph, taken near the summit of the Utsteinen nunatak on 26 December 2014 at 18:00 UTC and pointing west, shows the location of the two BIAs relative to PEA (b). 

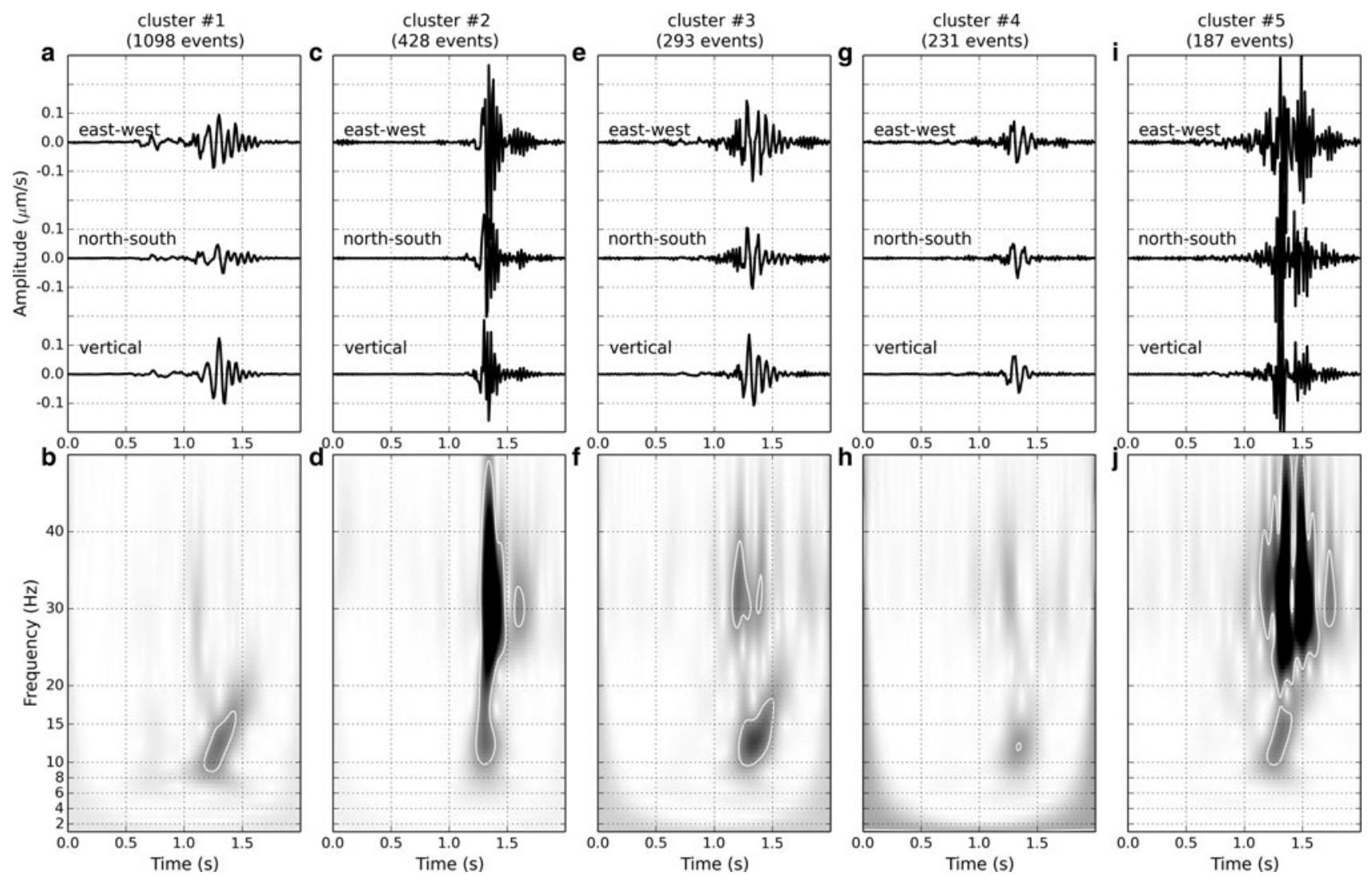

Fig. 2. Three component stacked traces for the five major clusters of seismic events $(\mathrm{a}, \mathrm{c}, \mathrm{e}, \mathrm{g}, \mathrm{i})$. The cluster number and the associated number of events are given. Spectrograms for the vertical component below each cluster traces $(b, d, f, h, j)$ indicate that all clusters present weak first arrivals, strong energy at $10-20 \mathrm{~Hz}$ with a dispersive character and signal of variable energy above $20 \mathrm{~Hz}$.

Starting from single-event clusters, the procedure iteratively creates agglomerative clusters of correlated events using the average method to characterize the distance between clusters. This procedure allowed the extraction of five major clusters of events, each gathering at least 100 events, representing a total of 2200 events, i.e. $50 \%$ of the original event dataset (Fig. 2). Overall, these events show a weak P-wave arrival followed by larger amplitude surface waves in the $10-20 \mathrm{~Hz}$ frequency range and some variable energy above $20 \mathrm{~Hz}$ depending on each cluster. No clear S-wave is observed. The signals are characterized by very short duration ( $<2$ seconds) and high-frequency content (up to the Nyquist frequency) suggesting a source located in the vicinity of the station, probably within a few $\mathrm{km}$. Based on the maximum duration of the seismic signal, we evaluated the maximum magnitude $M_{d}$ of this icequake to be $\sim 0.5$ (Lee and others, 1972).

\section{Temporal occurrence of icequakes}

The local ice around PEA is almost motionless, with a maximum ice flow speed $<2 \mathrm{~m} \mathrm{a}^{-1}$ (Pattyn and others, 2010; Rignot and others, 2011). This is likely the result of a combined effect of local bedrock topography together with the absence of any outlet glacier or ice stream in the close vicinity. This is confirmed by the absence of macro-scale crevasse fields in the vicinity of PEA (Fig. 1). The observed seismic events are therefore unlikely to be generated by dynamic processes related to ice flow suggesting instead a strong control by environmental factors such as ice/snow surface temperature variations. To test this hypothesis, we first inspected the monthly variations of the occurrence of these events, considering that the surface temperature may vary between summer (October-March, characterized by strong solar radiation) and winter (April-September, characterized by the polar night). For each month, the occurrence of the two major clusters gathering 1500 events, i.e. 3/4 of the dataset is merged to consider the dominant source mechanisms. This reveals that the total number of events per hour is two times larger in summer time than in winter time. This first observation leads us to investigate in more detail the monthly and daily variations of these cryoseismic signals through the analysis of hourly mean surface temperature estimated from longwave radiation measurements recorded at an automatic weather station (AWS) located $500 \mathrm{~m}$ south-east of the seismic station and installed on a snow surface (Gorodetskaya and others, 2013, 2015; Fig. 1a). Figure 3 shows that overall the highest number of events occurs when the snow surface temperature is the lowest. We also observe a clear diurnal modulation of the seismicity related to temperature for the summer months, the maximum amount of icequakes occurring at night. This diurnal modulation ceases in early winter (April-May), as the daily temperatures slowly decrease and the polar night sets in. The seismicity then seems to initiate only at a temperature below $-30{ }^{\circ} \mathrm{C}$. The winter period (JuneSeptember) is hence characterized by fewer seismic events, mostly clustered during few cold days when snow surface temperature drops below $-30^{\circ} \mathrm{C}$. Outside these cold days, seismicity is negligible.

These observations highlight a temperature dependence of the recorded seismicity. The observed seismic events 


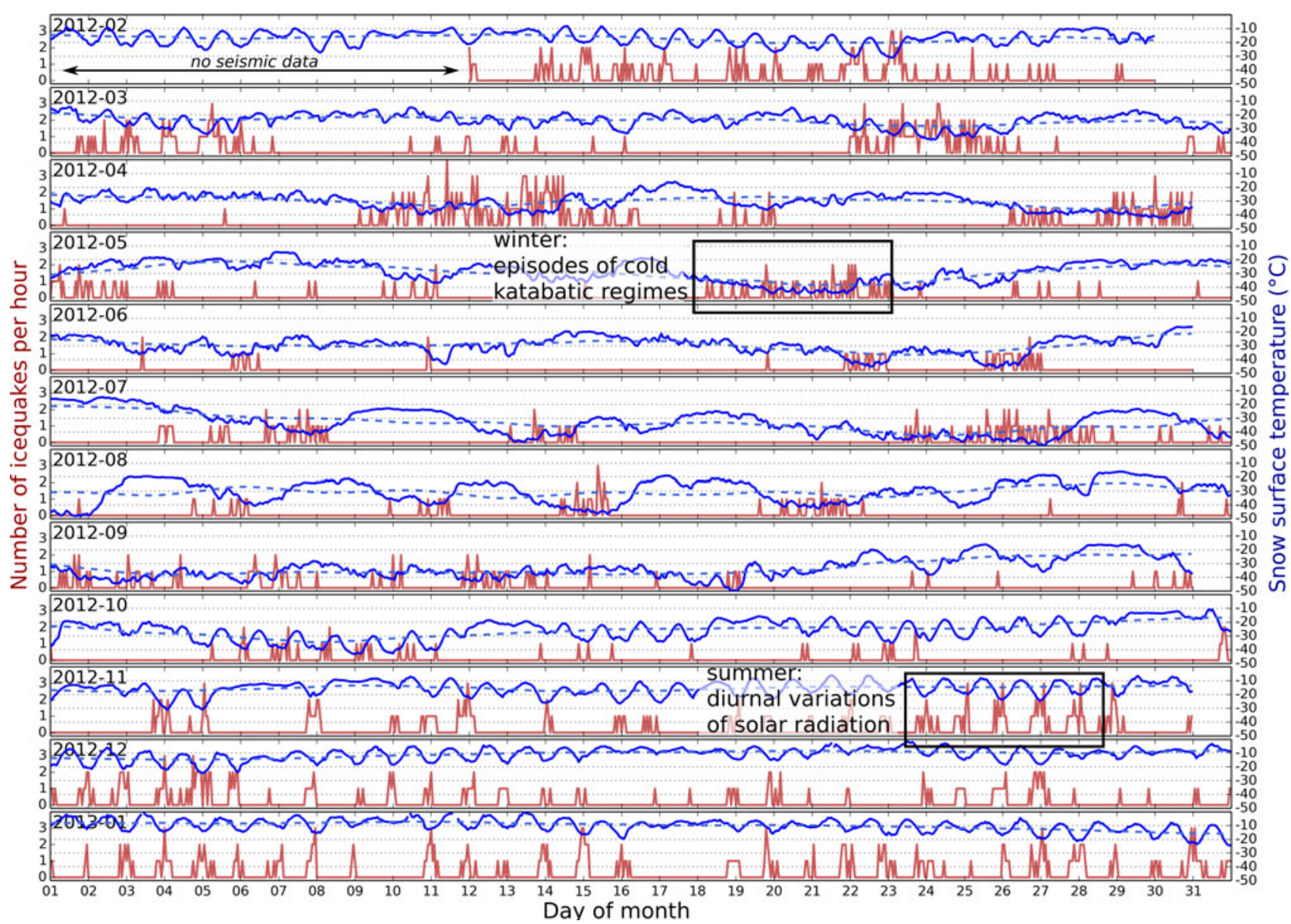

Fig. 3. Monthly variations of the number of seismic events per hour gathering the two major event clusters of Figure 2 (red) as a function of hourly mean snow surface temperature (blue, AWS data from Gorodetskaya and others, 2013). Snow surface temperature is calculated using measurements of outgoing longwave flux (LWout) emitted by the surface and using the relation LWout $=\epsilon . \sigma .\left(\mathrm{T}_{\text {snow_surface }}\right)^{4}$, where $\epsilon$ is snow emissivity assumed to be equaled to 0.98 (Wiscombe and Warren, 1980) and $\sigma$ is the Stefan-Boltzmann constant and equals $5.6704 \mathrm{~J} . \mathrm{s}^{-1} \cdot \mathrm{m}^{-2} \cdot \mathrm{K}^{-4}$. The weekly moving average ice surface temperature is shown as dashed blue line.

may, therefore, be attributed to the opening of surface cracks presumably generated by internal snow/firn/ice contraction during surface cooling periods. These particularly cold periods are observed with a daily recurrence in summer due to large diurnal variability in the incoming solar radiation and occasionally in winter characterized by katabatic winds from the Antarctic plateau and clear sky conditions associated with strong surface cooling. This is also illustrated by Figure 4 that displays the number of events for the two main clusters as a function of the time of the day together with the hourly temperature for three periods of the year and the annual mean.

During summer months (November-February, Figs 4a and $b$, yellow line) we clearly observe higher seismic activity at the beginning and at the end of the day, generally associated with the daily coldest temperature. There is a drastic decrease in seismic activity around midday when the daily temperatures are the warmest. For example, for cluster $\# 1$, in summer months, $85 \%$ of the events occur in the time interval 18:30-02:30 (Fig. 4a). Interestingly, for cluster \#2, to gather $85 \%$ of the events the time interval has to be enlarged for 3 hours (i.e., from 18:30 till 05:30, Fig. 4b). This peculiar observation is further addressed in the section Discussion ('Temporal occurrence'). Note, however, that for this period of the year (November-February), PEA is manned and therefore the number of seismic events recorded during the working hours (approximately from 07:00 till 19:00 UTC) is likely underestimated due to higher noise level present in the seismic data induced by higher anthropogenic activity. However, the drastic decrease of event number in the morning is most likely real as it initiates at $02: 30$ and 04:30 for cluster $\# 1$ and $\# 2$, respectively, i.e. well before the beginning of the working hours. If the observed seismic event distribution would be shaped by the lack of detection during daytime, due to anthropogenic noise, one would instead observe a step-like distribution starting 07:00 rather than the wide and smooth U-shape distribution as it is observed here. For mid-season (October and March, Figs $4 a$ and b, orange line) the decrease in the number of seismic events around midday is also observed but the overall decrease is less pronounced than for the summer months. During the winter period (AprilSeptember, Figs $4 a$ and b, blue line) there is no more temperature dependence of seismic events, their number being almost constant over the whole day. The effect of the wind on the initiation of events can be also discarded as it would generate continuous seismic noise rather than individual events as observed here (Withers and others, 1996). The wind would have an effect on the observations by lowering the signal-to-noise ratio, thus decreasing the total number of detected events. Additionally, at PEA, annual mean wind speed is relatively low compared to most places in 

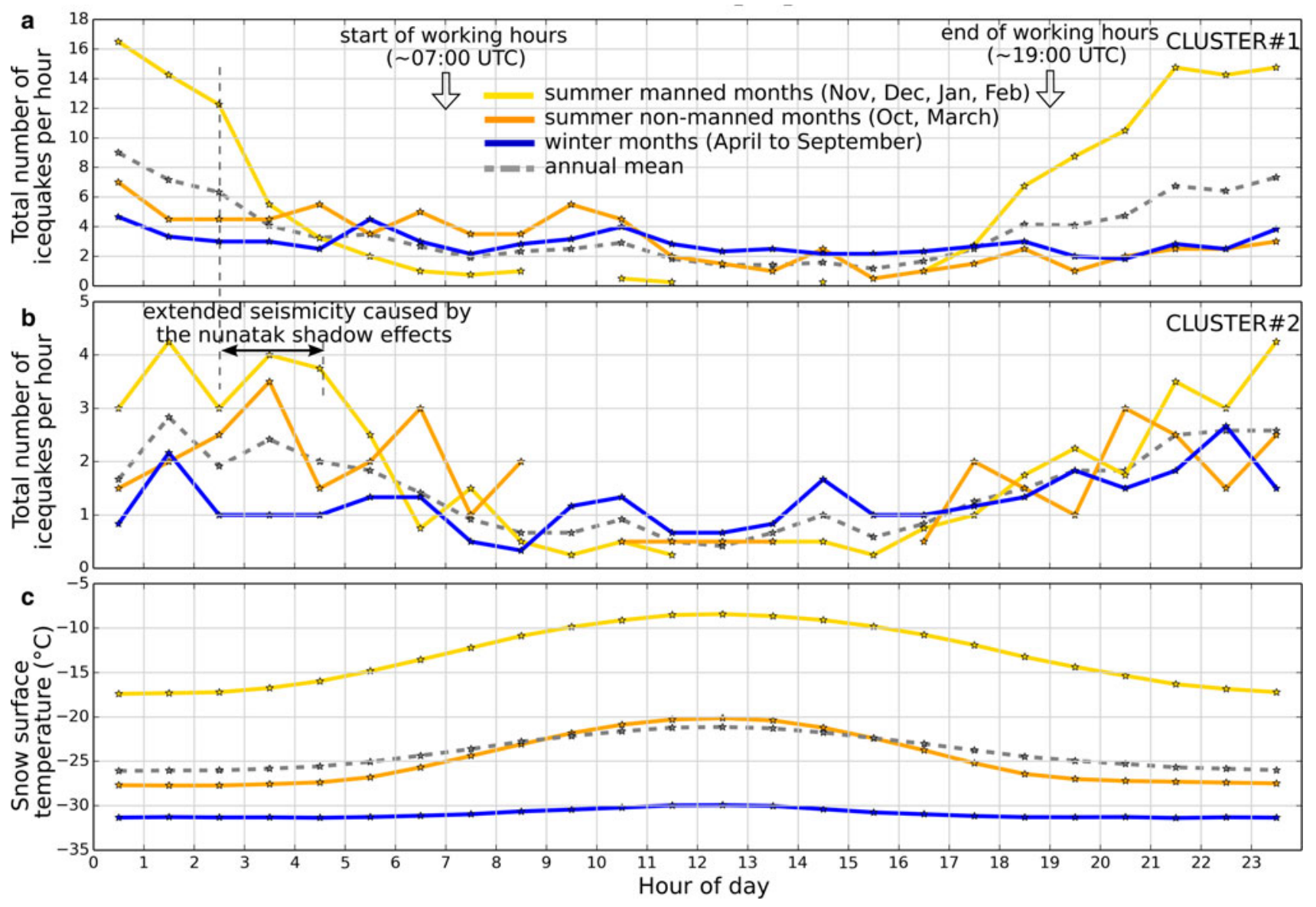

Fig. 4. Number of icequakes per hour per month for three periods of the year (summer manned and non-manned months, and winter) and for event cluster \#1 (a) and cluster \#2 (b). Mean hourly snow surface temperatures corresponding to each of three periods are shown in c (UTC time). The annual mean is also shown for each panel (dashed grey line). The few gaps within the lines indicate that no icequakes were detected at the corresponding time. The approximate start and end time of working hours (for the manned period) are marked by downward arrows (a). The period of extended seismicity for cluster $\# 2$ from 02:30 to 04:30 is also indicated (b).

Antarctica (Thiery and others, 2012; Gorodetskaya and others, 2013; Souverijns and others, 2018). For the time period considered here, the mean wind speed is $4.5 \mathrm{~m} \mathrm{~s}^{-1}$ with a slight increase to $5.0 \mathrm{~m} \mathrm{~s}^{-1}$ during the winter period. Indeed, the seismic dataset at PEA does not present any particularly higher noise due to wind perturbations in winter. Therefore, though it may lower the signal-to-noise ratio of the entire dataset, wind perturbations may affect summer and winter observations in a similar manner.

\section{Icequake signal waveforms and locations}

Our procedure of detection leads to two major clusters of icequakes representing $3 / 4$ of our initial dataset. The most abundant cluster \#1 clearly presents seismic signals of longer duration and lower frequency content than cluster \#2, suggesting the former may be generated by a more distant source, yet at few $\mathrm{km}$ to PEA. However, both clusters exhibit signals dominated by surface waves suggesting that both originate from sources located at the surface though recorded from different epicentral distances. Icequake signals present a weak emergent P-wave, no S-wave and well-defined surface waves arriving at 1.2-1.3 seconds and $0.2-0.3$ seconds after the P-wave onset for cluster \#1 and cluster \#2, respectively (Fig. 5). Overall, polarization analysis of the three components indicates a near horizontal propagation for the $\mathrm{P}$-wave and back-azimuths pointing to $\sim 255^{\circ}$ and $\sim 215^{\circ}$ for cluster $\# 1$ and cluster $\# 2$, respectively (Montalbetti and Kanasewich, 1970; Jurkevics, 1988). Surface waves present retrograde elliptical particle motion with varying polarization from elliptical to linear suggesting a propagation in a rather heterogeneous or/and anisotropic medium (Picotti and others, 2015; Diez and others, 2016).

Due to the dominance of the surface waves, the events highlighted in our study resemble the ones documented by Lough and others (2015). However, though weak, P-wave phases are visible in our dataset. Their absence in the observations of Lough and others (2015) was most likely due to attenuation over hundreds of $\mathrm{km}$ long epicentral distances. In the study of Nishio (1983), there is not enough information on the seismic waveform to allow such a comparison. Regarding our observations, the high-frequency content (i.e. $10-15 \mathrm{~Hz}$ ) of the surface waves indicates they probe the first tens of meters, i.e. uppermost firn layers confirming a shallow source (Picotti and others, 2015). This is also supported by the near-horizontal polarization of the first P-wave as illustrated by Figures $5 b$ and $d$. In order to quantify the source epicentral distance, we measured time delays between the P-wave and the surface wave arrivals. Such an approach is unfortunately limited to events with a large signal-to-noise ratio with clear $\mathrm{P}$-wave onset, representing here 95 and 38 events for cluster $\# 1$ and $\# 2$, respectively. The first P-wave can be reasonably assumed to propagate mostly within the uppermost bedrock layers since the 
a EXAMPLE ICEQUAKE FROM CLUSTER \# 1

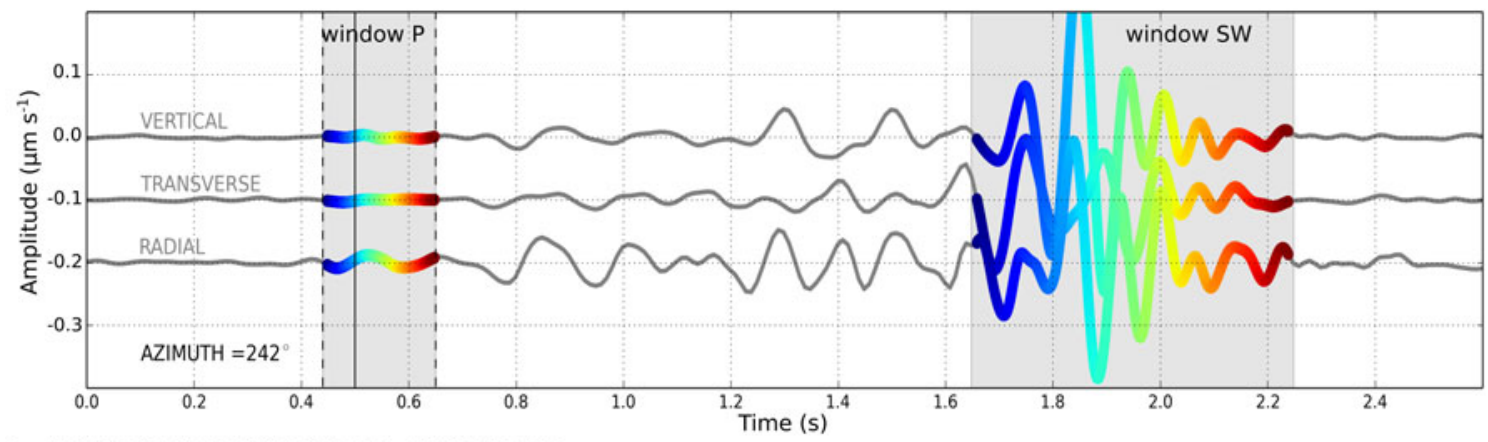

c EXAMPLE ICEQUAKE FROM CLUSTER \#2

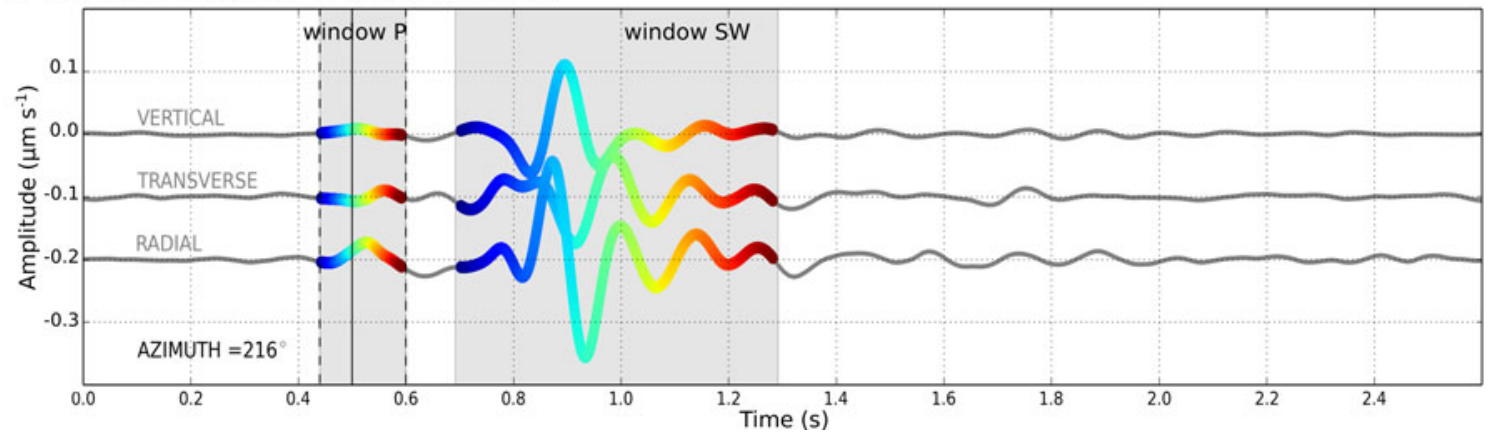

b

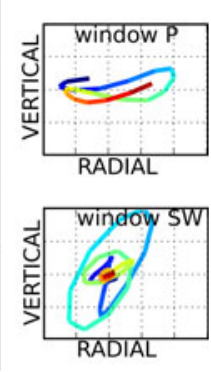

d

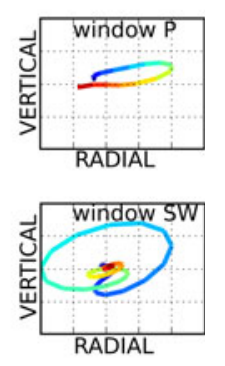

Fig. 5. Examples of two individual icequake events from cluster \#1 (a) and cluster \#2 (c). Three component seismograms are rotated into radial and transverse coordinates. Particle motion associated with time windows (shaded in grey in a and c) around the P-wave ('window $\left.\mathrm{P}^{\prime}\right)$ and the surface waves ('window SW') are shown in (b) and (d). Linear, near horizontal motions characterize the P-waves while retrograde elliptical motions indicate typical surface waves.

station lies on a rock outcrop and the rock basement around the station is shallow ( $<500 \mathrm{~m}$, Pattyn and others, 2010; Fretwell and others, 2013). We considered a range of P-wave velocities of $5.3-5.7 \mathrm{~km} \mathrm{~s}^{-1}$ with the upper limit being the mean value found for upper-crust propagation within the area (Camelbeeck and others, 2019). While the P-wave travels through the uppermost bedrock layers, the surface waves, as pointed out previously, likely probe the firn layers, propagating at velocities in the range 1400-1600 $\mathrm{m} \mathrm{s}^{-1}$ when considering 10-15 Hz surface waves (Fig. 9 of Picotti and others, 2015; Diez and others, 2016). Combining these velocities, the time delays between the P-wave and the surface wave arrivals, together with the azimuthal information from polarization analysis (Fig. 5) provide a reasonable estimate of possible icequake locations with uncertainties in the order of \pm 0.5 and $\pm 0.25 \mathrm{~km}$ for cluster $\# 1$ and cluster \#2, respectively. The event locations focus univocally towards a rectangle shaped blue ice area (BIA) and towards the Utsteinen nunatak and its surrounding wind-carved BIAs located $4 \mathrm{~km}$ south-west and $1 \mathrm{~km}$ south-south-west of the station for cluster $\# 1$ and cluster $\# 2$, respectively (Fig. 1). Interestingly, while located about three times closer to PEA, cluster \#2 exhibits about two times fewer icequakes than cluster \#1. This may be due to a complex subsurface propagation caused by the presence of a three-dimensional bedrock structure, reflected at the surface by the pyramidshaped Utsteinen nunatak. This complex propagation may result in varying seismic waveforms and fewer detections for cluster \#1. With their location on the leeward side of the nunatak, these two BIAs likely result from wind scouring effects on the surface, removing readily any deposited snow (BIA of type I in Bintanja, 1999). We attribute the observed seismicity to be generated by these BIAs responding to thermal cooling of the surface. This does not imply there are no thermal icequakes within the snow/firn covered areas surrounding the seismic station. If any, they may not be located in confined areas but may rather be spread all around the station, generating varying waveforms and thus may not be detected via our waveform pattern recognition procedure.

\section{DISCUSSION}

\section{Temporal occurrence}

Over the year-long dataset, 1500 seismic events were detected and categorized into two clusters based on their seismic waveforms and durations. Their source location on two BIAs and their dependence on large diurnal temperature variability mainly due to daily solar radiation in summer or cold katabatic regime in winter suggest they are associated with thermal contraction of blue ice. Our dataset shows a clear temporal pattern of icequake occurrence that deserves to be discussed in the light of the few previous analyses of similar events. In the study of Lough and others (2015) no systematic and long-term temporal analysis was unfortunately provided as the dataset originated from short-term experiments. However, a high rate of 'firnquake' activity was observed during the onset of the Antarctic winter consistent with thermal contraction. Regarding the study at the inland Mizuho base by Nishio (1983), a detailed analysis of the temporal occurrence of the so-called 'snowquakes' was provided and appears similar to ours. The author showed that the 'snowquakes' activity suddenly occur when temperature starts to decrease in the early afternoon, reaches a peak at night and progressively ceases in the morning. The 'snowquake' activity is described as irregular during winter, modulated by the inland high atmospheric pressure system. 
It presents, however, a diurnal modulation in early summer (mid-September to the end of November), due to variation in daily solar radiation. Surprisingly, the author observes that the activity ceases in summer (end of November to early January) where one would expect abundant seismicity due to large temperature fluctuations as in our study. Nishio explains this observation by the dominant ductile deformation of snow for temperature above $-20{ }^{\circ} \mathrm{C}$, a phenomenon not seen for instance in the most recent studies by Podolskiy and others (2018) and MacAyeal and others (2018). However, at Mizuho base, the surface conditions and mean air and surface temperatures differ significantly from these two studies. Our observations, which also do not present such a lack of seismicity at these warm temperatures, may indicate that icequake sources are likely located in a medium different from the snow, i.e. ice.

Interestingly, a closer look at the daily occurrence of our two clusters reveals that the seismicity rate decrease we observe in the morning does not occur at the same time as one would expect for two close-by ice surfaces with similar rheological properties (Fig. 4). Indeed, considering the summer period, while the number of events from cluster \#1 drops at 02:30 AM, cluster \#2 starts decreasing 2 hours later. Images from a webcam pointing towards the Utsteinen nunatak confirms that, during summertime in early morning, the BIAs of cluster \#2 is shadowed by the $300 \mathrm{~m}$ high (above ice surface) nunatak for 2 hours after sunrise (Fig. 1 bottom right inset, Gorodetskaya and others, 2015), leading to cold temperature persistent for two additional hours on BIA \#2 while BIA \#1 is already receiving solar radiation. This delay is not observed in the late afternoon when the seismicity initiates simultaneously for both clusters. Indeed, in the late afternoon, both BIAs, located on the western side of the nunatak, undergo the same solar radiation decrease with no obstacle creating any shadow effect (Fig. 1b). This observation of a 2 hour delay in the decrease of seismicity further supports the location of cluster $\# 2$ on the western flank of the nunatak. It, therefore, favors the interpretation of icequake induced by thermal stress variations, controlled in summer by the solar radiation over the blue ice.

\section{Dependence on absolute temperature and on its temporal change}

Our year-long analysis of icequakes shows that most of our events occur during summer time when the daily mean temperature variability is significant, i.e. $>10^{\circ} \mathrm{C}$, due to significant incoming solar radiation variations (Fig. 4, yellow curve). Yet, our detection shows that about one-third of our events occur in the winter period when daily temperature fluctuations are rather small (Fig. 4, blue curve). These observations lead us to address the question of the absolute temperature dependence of those icequakes by analyzing their number and amplitude for daily mean surface temperature $T_{\text {mean }}$ and mean temperature change $\partial T / \partial t$ (Fig. 6). Having determined that the observed icequakes are originating from two BIAs and lacking meteorological measurements directly at the BIAs, we use the measured snow surface temperature in the AWS site located $1 \mathrm{~km}$ from the nearest BIA to infer temperature variability. In order to relate to the BIAs temperature, we use measurements on the BIA and on the snow surface in a similar environment at Svea station (see Appendix A, Figs 8 and 9). In summer, BIA surface temperature may be several degrees warmer than snow (Takahashi and others, 1992; Bintanja and van den Broeke, 1995; Bintanja, 2000), owing to its lower albedo value (i.e. $\sim 0.6$ compared to $>0.78$ for fresh snow, e.g. Winther and others, 1996; Reijmer and others, 2001). This is demonstrated by Figure 9a for Svea site. Stronger surface radiative heating, together with higher thermal conductivity and lower extinction coefficient of blue ice compared to snow
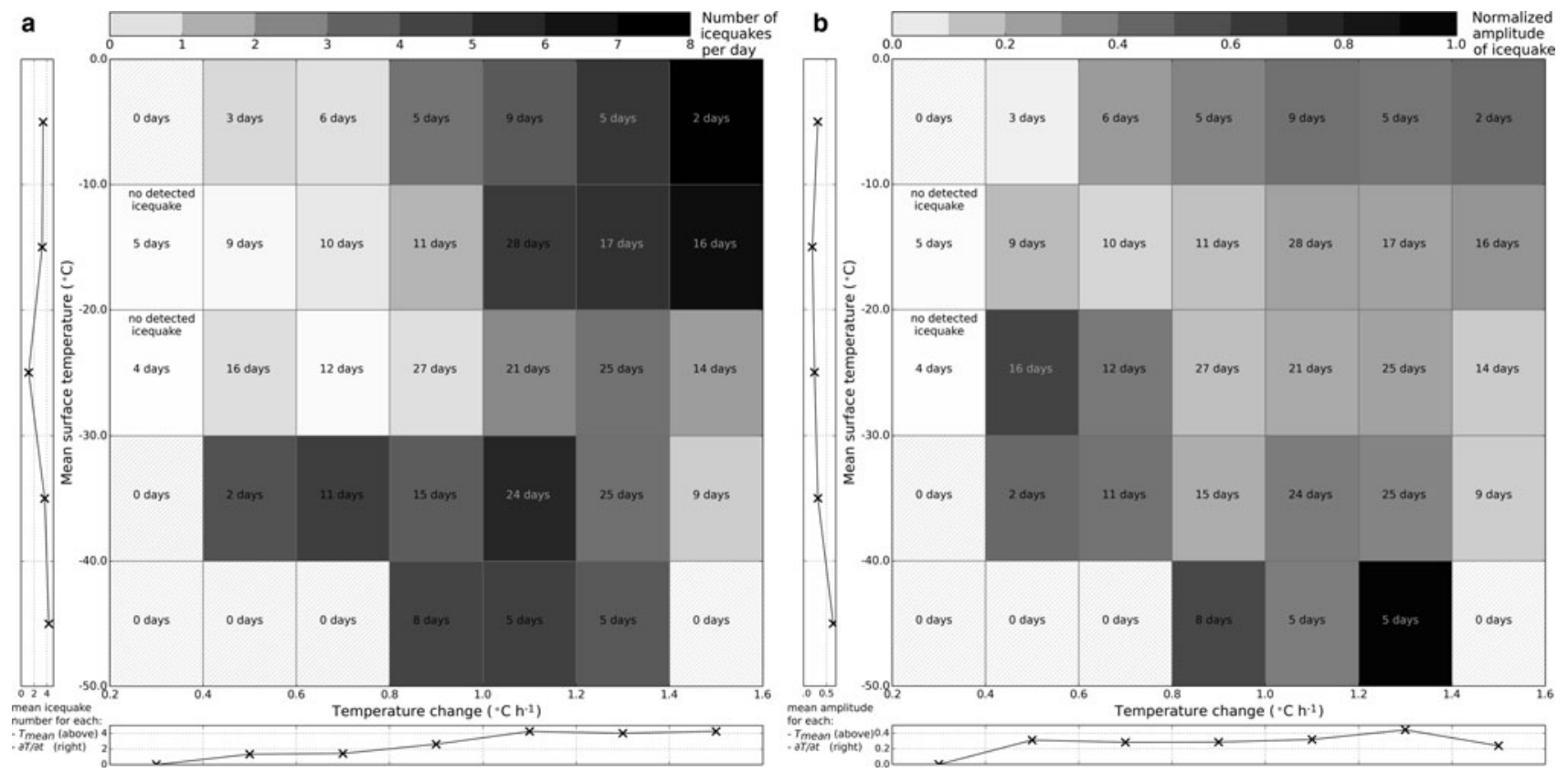

Fig. 6. Distribution of number (a) and normalized RMS amplitude (b) of cluster\#1 icequakes for mean surface temperature $T_{\text {mean }}$ (vertical axis) and hourly temperature change $\partial \mathrm{T} / \partial \mathrm{t}$ (horizontal axis). Values are given by the top color bars. The number ( $n$ days) within each box indicates the numbers of days where icequakes were detected. Label ' 0 days' means that the year 2012 did not contain such a pair of $T_{\text {mean }}$ and $\partial T / \partial t$. The side panels represent the mean value for each $\mathrm{T}_{\text {mean }}$ (left vertical panel) and for each $\partial \mathrm{T} / \partial \mathrm{t}$ (bottom horizontal panel). The rate of temperature change is defined as the mean temperature decrease per hour per day. 

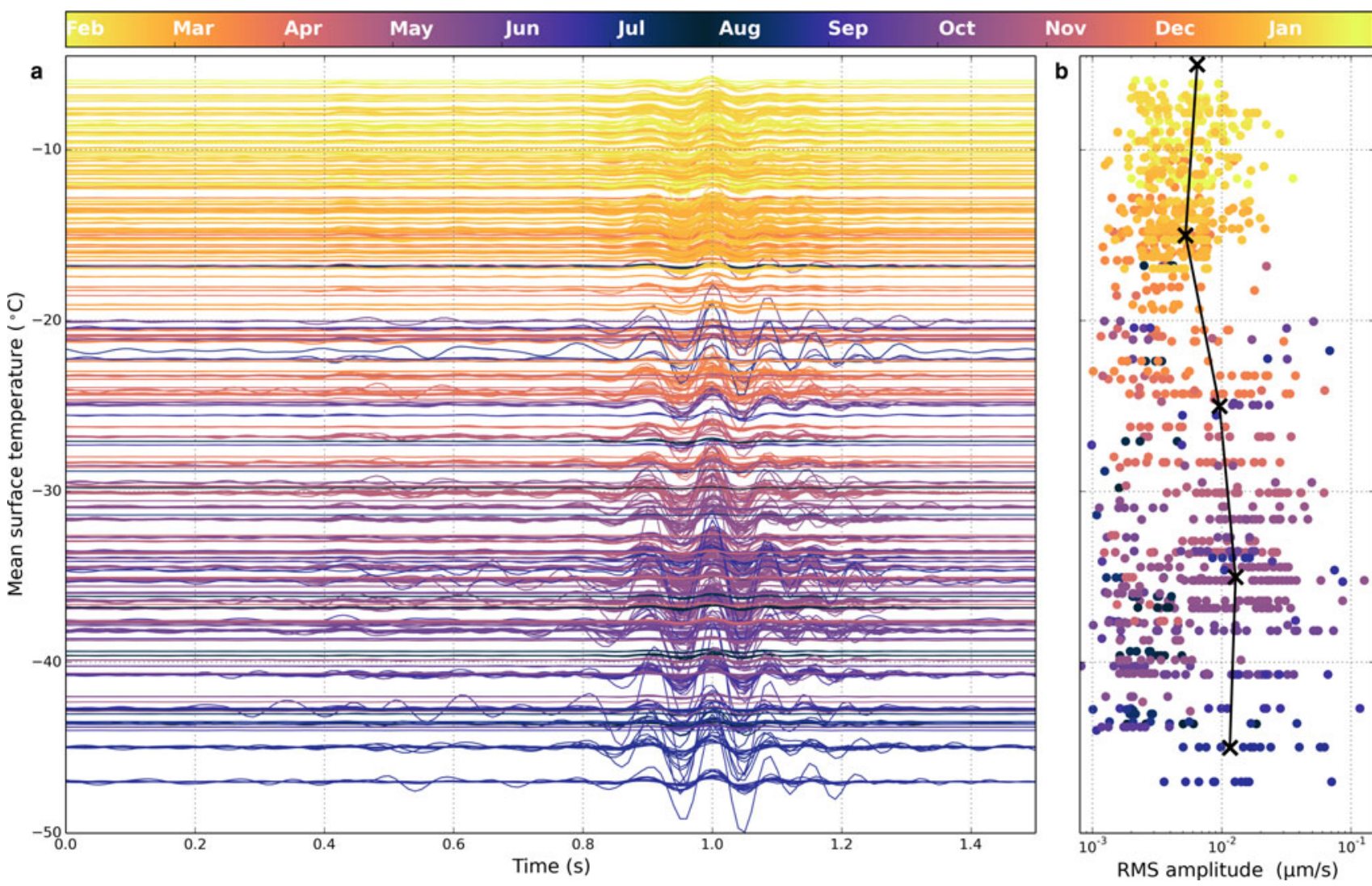

Fig. 7. Vertical component of seismic traces (a) and associated RMS amplitude (b) of cluster \#1 icequakes sorted as a function of daily mean temperature. The connected crosses in (b) indicate the mean RMS amplitude for each temperature bin as defined in Figure 6 . Color represents the time of the year as indicated in the top color bar.

(Yen, 1981; Fukusako, 1990) result in warmer ice subsurface layers ( $<1 \mathrm{~m}$ depth) that undergo higher temperature change at least in summer time when solar radiation is maximum (Bøggild and others, 1995; Bintanja, 2000). Indeed, reported observations indicate that the daily temperature fluctuations induced by solar radiation penetrates the ice down to $80 \mathrm{~cm}$ depth while this penetration depth is about twice shallower for snow layers (Nishio, 1983; Bintanja, 2000). On the other hand, in winter, the snow surface temperature is primarily controlled by longwave radiation and turbulent fluxes which do not depend on the ground albedo. However, both longwave radiative and turbulent fluxes vary strongly with the alternation of cold katabatic and warm synoptic regimes affecting both the snow and BIAs (Thiery and others, 2012; Gorodetskaya and others, 2013; Souverijns and others, 2018). Our analysis at Svea (Fig. 9) showed that for winter periods, snow and ice surface temperature show similar absolute values and synoptic-scale variability, while subsurface temperatures (initially installed at $10 \mathrm{~cm}$ depth) at BIA show colder minimum temperatures and warmer maximum temperatures compared to the snow site (this can be caused also by increase in the depth at the snow site due to snow accumulation subduing the subsurface temperature variability).

Bearing these considerations in mind, we present in Figure 6 the variations of icequake number and amplitude for the most abundant cluster \#1 as a function of surface temperature and its time derivative, as estimated on the snow surface at the AWS site, $500 \mathrm{~m}$ south-east of PEA. These summarizing heatmap representations show that for the increasing rate of temperature change, we observe increasing icequake numbers (Fig. 6a, bottom horizontal panel). This is observed for all temperature ranges except for extremely cold temperature, i.e. $<-30{ }^{\circ} \mathrm{C}$, corresponding to the end of summer. There, the initiation of seismicity is more rapid (Fig. 6a, left vertical panel) i.e. the icequake number is significant even for small rate of change, for example, there are four icequakes per day for $0.4-0.6^{\circ} \mathrm{C} \mathrm{h}^{-1}$ at $T_{\text {mean }}=-30^{\circ}$ to $-40{ }^{\circ} \mathrm{C}$ while there are only 0.5 icequakes per day for the same rate at $T_{\text {mean }}=-20^{\circ}$ to $-30^{\circ} \mathrm{C}$. Regarding the distribution of icequake amplitude, no particular correlation with the temperature change is observed (Fig $6 b$, bottom horizontal panel). However, seismic amplitudes appear to be anticorrelated with temperature (Fig. 6b, left vertical panel). This observation is well illustrated in Figure 7 that presents the vertical component of seismic traces for cluster \#1 as a function of the daily mean temperature. For 'warm' temperature, i.e. $\mathrm{T}_{\text {mean }}>-20{ }^{\circ} \mathrm{C}$, icequakes are characterized by low amplitudes and small variability (Fig 7). In contrast, when the temperature drops below $\sim-20^{\circ} \mathrm{C}$, the icequake amplitude increases, so as its variability among various events. Considering that all detected icequakes shown in Figure 7 originate from the same source location (Fig. 1, BIA \#1), and therefore that the amplitude variations are not caused by varying epicentral distances, this indicates a clear link between the seismic energy released by thermal icequakes and the surface temperature.

Ice rheology proscribes thermally induced strain rate initiation of new fractures to explain the origin of icequakes. Indeed, the thermal strain rate (defined as $\dot{\varepsilon}=\alpha . \partial T / \partial t$ with $\alpha \approx 5.10^{-5}{ }^{\circ} \mathrm{C}^{-1}$ being the coefficient of thermal expansion of ice (Butkovich, 1959)) is of the order of $10^{-8} \mathrm{~s}^{-1}$, i.e. 
at least one order of magnitude below the ductile - brittle transition of ice (Schulson and others, 1984; Lee and Schulson, 1988). Therefore, BIAs likely accommodate the induced thermal stress mostly via elastic or creep deformation (Sanderson, 1978) and, as described hereafter, via reactivation of pre-existing fractures. Indeed, to explain our detected seismicity, considering the previous observations (Figs 6 and 7), we propose the following processes. The relatively sudden increase of icequake number for temperatures $<-30{ }^{\circ} \mathrm{C}$, contrasting with a slow increase towards higher rate of temperature change for warmer temperatures (Fig. 6a), may indicate a change in the mechanism at the origin of the icequakes rather than a change in the ice properties that would not be so abrupt. Considering that thermal icequakes are likely due to cyclic opening/closing of existing superficial cracks (Nishio, 1983), we surmise here that, at the end of summer (end of March), when solar radiation ceases and temperatures remain below $-30{ }^{\circ} \mathrm{C}$ for longer time periods (from several days to more than a week), opened cracks prevail. We postulate that the underlying mechanism in triggering the icequakes is the propagation of fractures at the tips of the opened cracks where stress concentrates. This differs substantially from the nocturnal re-opening of pre-existing cracks, prevalent during summer. Furthermore, at a constant fabric and grain size, the temperature is a major controlling factor of the ice rheology. As the temperature decreases, the effective viscosity of ice increases significantly, for example, by a factor of 5 for a temperature drop from -10 to $-25^{\circ} \mathrm{C}$ (Cuffey and Paterson, 2010). The ice becomes stiffer and may support higher stress before failure. The stress relaxation may occur through large amplitude icequakes, which may explain the progressive increase in amplitude of icequakes with decreasing temperature (Fig 6b, vertical left panel).

In the absence of more quantitative information on the blue ice temperature and on direct thermal crack observations nearby PEA, these interpretations remain open to discussion. Indeed, as discussed already (see the Appendix for details), the warm temperatures presented in Figure 6 most likely underestimate the actual blue ice temperatures, and may occasionally approach the ice melting point (see also the Appendix Fig. 8 comparing blue ice and snow temperatures at Svea station). Localized surface ice melting and refreezing may occur and participate in crack healing (Colbeck, 1986). As an opposite mechanism, thermal fatigue may play an important role in creating flaws and microcracks, lowering the ice tensile strength, thus weakening the ice surface, in a way similar to rock weathering (Hall, 1999; Lamp and others, 2017). To obtain more complete insights on the thermal icequakes and on blue ice rheology, a more relevant and dedicated experiment conducted over such BIAs using a multidisciplinary approach should be conducted, including detailed vertical temperature logging in the blue ice.

\section{CONCLUSIONS}

By analyzing 1 year of continuous seismic data recorded at the Princess Elisabeth base in East-Antarctica, we detected thousands of icequakes most likely related to thermal stress and affecting two narrow areas in the vicinity of the base, each characterized by outcropping blue ice. Our measurements showed that summer daily solar radiation variations inducing large surface temperature variability and winter surface cooling during the cold katabatic regime, are the main environmental mechanisms triggering this temperature-related icequake seismicity. Investigations on the occurrence of these icequakes indicate that their properties are dependent on both the absolute surface temperature and its time derivative. In this regard, they can be viewed as an opportunity to monitor the thermal state of ablation zones. We surmise that thermal icequakes are abundant in cryoseismic datasets but are often regarded as noise perturbations and rejected from further investigation. To obtain more complete insights into thermal icequakes and underlying ice fracture mechanics, and to assess the potential of passive seismology to monitor the surface thermal state, we encourage dedicated and integrated studies on both BIAs and snow/ firn cover.

\section{ACKNOWLEDGEMENTS}

We acknowledge the support of the Belgian Antarctic program lead by the Belgian Federal Science Policy (BELSPO) allowing the installation and maintenance of the seismic station (project GIANT-LISSA, grants EA/33/2A and EA/33/2B). We are thankful to the BELSPO project HYDRANT (grants EA/01/04A and EA/01/04B, PI Nicole van Lipzig) that supported installation and maintenance of the automatic weather station at PEA together with technical support by the Institute for Marine and Atmospheric Research (IMAU), Utrecht University. We thank Carleen Reijmer (IMAU) for providing AWS6 and AWS7 data at Svea base. Niels Souverijns is acknowledged for providing access to the webcam data now supported under BELSPO project AEROCLOUD. We are grateful to the International Polar Foundation for the logistic and field support in such a difficult environment. We are also grateful for constant development of the following open-source software packages used in this study: Python (python.org), Matplotlib (Hunter, 2007), Obspy (Beyreuther and others, 2010) and QGIS (qgis.org). We also benefited from the Quantarctica database distributed by the Norwegian Polar Institute (quantarctica.org). IG thanks FCT/MCTES for the financial support to CESAM (UID/AMB/50017/2019), through national funds. We thank Trevor Williams for proofreading the manuscript while at sea. The manuscript profited from constructive reviews from Evgeny Podolskiy and an anonymous reviewer. This is IPGP contribution 4044.

\section{REFERENCES}

Allen RV (1978) Automatic earthquake recognition and timing from single traces. Bull. Seismol. Soc. Am., 68(5), 1521-1532

Aster RC and Winberry JP (2017) Glacial seismology. Rep. Prog. Phys., 80(12), 126801

Barruol G and 5 others (2013) Tide-induced microseismicity in the Mertz glacier grounding area, East Antarctica. Geophys. Res. Lett., 40(20), 5412-5416

Bassis JN and 7 others (2007) Seismicity and deformation associated with ice-shelf rift propagation. J. Glaciol., 53(183), 523-536

Beyreuther $M$ and 5 others (2010) Obspy: a python toolbox for seismology. Seismological Res. Lett., 81(3), 530-533 (doi: 10.1785/ gssrl.81.3.530)

Bintanja R (1999) On the glaciological, meteorological, and climatological significance of Antarctic blue ice areas. Rev. Geophys., 37(3), 337-359

Bintanja R (2000) Surface heat budget of Antarctic snow and blue ice: interpretation of spatial and temporal variability. J. Geophys. Res.: Atmos., 105(D19), 24387-24407 
Bintanja R and van den Broeke MR (1995) The surface energy balance of Antarctic snow and blue ice. J. Appl. Meteorol., 34 (4), 902-926

Bøggild CE, Winther J-G, Sand K and Elvehøy H (1995) Sub-surface melting in blue-ice fields in Dronning Maud Land, Antarctica: observations and modelling. Ann. Glaciol., 21, 162-168

Butkovich T (1959) Thermal expansion of ice. J. Appl. Phys., 30, 350

Camelbeeck T, Lombardi D, Collin F, Rapagnani G and Martin H (2019) Icequake observation at the edge of the Antarctic plateau, in prep

Colbeck SC (1986) Theory of microfracture healing in ice. Acta Metall., 34(1), 89-95

Crary A (1955) A brief study of ice tremors. Bull. Seismol. Soc. Am., 45(1), 1-9

Cuffey KM and Paterson WSB (2010) The Physics of Glaciers, 4th Edition, Butterworth-Heinemann/Elsevier

Diez A and 8 others (2016) Ice shelf structure derived from dispersion curve analysis of ambient seismic noise, Ross Ice Shelf, Antarctica. Geophys. J. Int., 205(2), 785-795

Ferrari C (2018) Thermal properties of icy surfaces in the outer solar system. Space Sci. Rev., 214(8), 111

Fretwell P and 59 others (2013) Bedmap2: improved ice bed, surface and thickness datasets for Antarctica. Cryosphere, 7, 375-393

Fukusako S (1990) Thermophysical properties of ice, snow, and sea ice. Int. J. Thermophys., 11(2), 353-372

Gorodetskaya IV and 5 others (2013) Meteorological regimes and accumulation patterns at Utsteinen, Dronning Maud Land, East Antarctica: analysis of two contrasting years. J. Geophys. Res.: Atmos., 118(4), 1700-1715

Gorodetskaya IV and 8 others (2015) Cloud and precipitation properties from ground-based remote-sensing instruments in East Antarctica. Cryosphere, 9(1), 285-304

Hall K (1999) The role of thermal stress fatigue in the breakdown of rock in cold regions. Geomorphology, 31(1-4), 47-63

Heeszel DS, Fricker HA, Bassis JN, O'Neel S and Walter F (2014) Seismicity within a propagating ice shelf rift: the relationship between icequake locations and ice shelf structure. J. Geophys. Res. Earth Surf., 119, 731-744

Hunter JD (2007) Matplotlib: a 2D graphics environment. Comput. Sci. Eng., 9, 90-95

Jurkevics A (1988) Polarization analysis of three-component array data. Bull. Seismol. Soc. Am., 78(5), 1725-1743

Lamp JL, Marchant DR, Mackay SL and Head JW (2017) Thermal stress weathering and the spalling of Antarctic rocks. J. Geophys. Res. Earth Surf., 122, 3-24

Lee W, Bennett R and Meagher K (1972) A method of estimating magnitude of local earthquakes from signal duration. U.S. Geol. Surv. Open File Rep. 28, 1-29

Lee RW and Schulson EM (1988) The strength and ductility of ice under tension. J. Offshore Mech. Arct. Eng., 110(2), 187-191

Lewis JK (1994) Relating Arctic ambient noise to thermally induced fracturing of the ice pack. J. Acoust. Soc. Am., 95(3), 1378-1385

Lombardi D and 5 others (2016) Bimodal pattern of seismicity detected at the ocean margin of an Antarctic ice shelf. Geophys. J. Int., 206(2), 1375-1381

Lough AC, Barcheck CG, Wiens DA, Nyblade A and Anandakrishnan S (2015) A previously unreported type of seismic source in the firn layer of the East Antarctic Ice Sheet. J. Geophys. Res.: Earth Surf., 120(11), 2237-2252

MacAyeal DR and 6 others (2018) Diurnal seismicity cycle linked to subsurface melting on an ice shelf. Ann. Glaciol. 60(79), 1-21

Mikesell T and 5 others (2012) Monitoring glacier surface seismicity in time and space using Rayleigh waves. J. Geophys. Res.: Earth Surf., 117(F2)

Milne A (1972) Thermal tension cracking in sea ice: a source of under ice noise. J. Geophys. Res., 77(12), 2177-2192

Montalbetti JF and Kanasewich ER (1970) Enhancement of teleseismic body phases with a polarization filter. Geophys. J. Int., 21(2), 119-129
Neave K and Savage J (1970) Icequakes on the Athabasca glacier. J. Geophys. Res., 75(8), 1351-1362

Nishio F (1983) Studies on thermally induced fractures and snowquakes of polar snow cover. Memoirs of National Institute of Polar Res. Ser. C, 14, 1-48

Panning MP and 7 others (2018) Expected seismicity and the seismic noise environment of Europa. J. Geophys. Res.: Planets, 123(1), 163-179

Pattyn F, Matsuoka K and Berte J (2010) Glacio-meteorological conditions in the vicinity of the Belgian Princess Elisabeth Station, Antarctica. Antarct. Sci., 22(1), 79-85

Picotti S, Vuan A, Carcione JM, Horgan HJ and Anandakrishnan S (2015) Anisotropy and crystalline fabric of Whillans Ice Stream (West Antarctica) inferred from multicomponent seismic data. J. Geophys. Res.: Solid Earth, 120(6), 4237-4262

Podolskiy EA, Fujita K, Sunako S, Tsushima A and Kayastha RB (2018) Nocturnal thermal fracturing of a Himalayan debriscovered glacier revealed by ambient seismic noise. Geophys. Res. Lett., 45(18), 9699-9709

Podolskiy EA and Walter F (2016) Cryoseismology. Rev. Geophys., 54(4), 708-758

Reijmer C, Bintanja R and Greuell W (2001) Surface albedo measurements over snow and blue ice in thematic mapper bands 2 and 4 in Dronning Maud Land, Antarctica. J. Geophys. Res.: Atmos., 106(D9), 9661-9672

Rignot E, Mouginot J and Scheuchl B (2011) Ice flow of the Antarctic ice sheet. Science, 333 (doi: (10.1126/science.1208336)

Röösli C and 6 others (2014) Sustained seismic tremors and icequakes detected in the ablation zone of the Greenland ice sheet. I. Glaciol., 60(221), 563-575

Sanderson TJO (1978) Thermal stresses near the surface of a glacier. J. Glaciol., 20(83), 257-283 (doi: 10.3189/S0022143000013836)

Schulson EM, Lim P and Lee R (1984) A brittle to ductile transition in ice under tension. Philos. Mag. A, 49(3), 353-363

Souverijns $N$ and 7 others (2018) How does the ice sheet surface mass balance relate to snowfall? Insights from a ground-based precipitation radar in East Antarctica. Cryosphere, 12(6), 19872003

Takahashi S, Endoh T, Azuma N and Meshida S (1992) Bare ice fields developed in the inland part of Antarctica. Proc. NIPR Symp. Polar Meteorol. Glaciol. 5, 128-139

Thiery W and 7 others (2012) Surface and snowdrift sublimation at Princess Elisabeth station, East Antarctica. Cryosphere, 6(2), 841-857

Vance SD and 11 others (2018) Vital signs: seismology of icy ocean worlds. Astrobiology, 18(1), 37-53

van den Broeke MR, Reijmer C, Van As D, Van de Wal R and Oerlemans J (2005) Seasonal cycles of Antarctic surface energy balance from automatic weather stations. Ann. Glaciol., 41(4), 131-139 http://doi.org/10.3189/172756405781813168

von der Osten-Woldenburg H (1990) Icequakes on Ekström ice shelf near Atka Bay, Antarctica. J. Glaciol., 36(122), 31-36

Walter $F$ and 5 others (2009) Moment tensor inversions of icequakes on Gornergletscher, Switzerland. Bull. Seismol. Soc. Am., 99(2A), 852-870

Winther J-G, Elvehøy H, Bøggild CE, Sand K and Liston G (1996) Melting, runoff and the formation of frozen lakes in a mixed snow and blue-ice field in Dronning Maud Land, Antarctica. J. Glaciol., 42(141), 271-278

Wiscombe WJ and Warren SG (1980) A model for the spectral albedo of snow. I: pure snow. J. Atmos. Sci., 37(12), 2712-2733

Withers MM, Aster RC, Young CJ and Chael EP (1996) High-frequency analysis of seismic background noise as a function of wind speed and shallow depth. Bull. Seismol. Soc. Am., 86(5), 1507-1515

Xie $Y$ and Farmer DM (1991) Acoustical radiation from thermally stressed sea ice. J. Acoust. Soc. Am., 89(5), 2215-2231

Yen Y-C (1981) Review of thermal properties of snow, ice and sea ice, CRREL Rep. 81-10 Cold Regions Research and Engineering Lab, Hanover $\mathrm{NH}$ 


\section{APPENDIX A \\ SNOW AND BLUE ICE TEMPERATURES AT SVEA STATION}

In the absence of temperature measurements at BIAs, our study uses the dataset from the AWS16 located on a snow surface nearby PEA. In order to compare snow and blue ice surface temperature behavior, we used data from AWS (developed by the Institute for Marine and Atmospheric Research - IMAU) nearby Svea station $\left(74^{\circ} 35^{\prime} \mathrm{S}, 11^{\circ} 13^{\prime} \mathrm{W}\right)$ located in the escarpment zone of the East Antarctic ice sheet, $350 \mathrm{~km}$ from the coast at elevation $1261 \mathrm{~m}$ a.s.l. with mountains nearby (Bintanja, 2000), which is a similar environment to PEA. We compared surface and subsurface temperatures derived from an AWS located on the snow surface and from an AWS located in the BIA (IMAU AWS6 and AWS7 installed at sites 3 and 1, respectively, as described by Bintanja, 2000) (Figs 8 and 9). Snow and blue ice surface temperatures were calculated using 2-hourly mean measurements of broadband longwave radiative fluxes by pyrradiometers (for sensor description, see van den Broeke and others, 2005). Subsurface temperatures were measured using thermocouples initially installed at the depths of 5, 10, 20, 40 and $80 \mathrm{~cm}$ on 14 January 1998 at AWS6 and on 07 January 1998 at AWS7. Figure 8 shows surface temperature and subsurface temperatures down to $80 \mathrm{~cm}$ (initial installation depth) as measured at the snow and blue ice sites. Figure 9 compares surface and subsurface temperatures at the initial depth of $10 \mathrm{~cm}$ at the snow and blue ice sites. Pearson correlation coefficient between the surface temperatures at two sites is 0.95 (significant at $99 \%$ confidence interval).

During summer months (here January-February when measurements at both sites are available), blue ice surface temperature is much warmer both during its diurnal maximum and minimum (on average by 5.6 and $4.6^{\circ} \mathrm{C}$ for daily maximum and minimum temperatures, accordingly) leading to an average daily amplitude of surface temperatures over blue ice $1{ }^{\circ} \mathrm{C}$ larger compared to snow surface. In winter, icequakes are not associated with diurnal
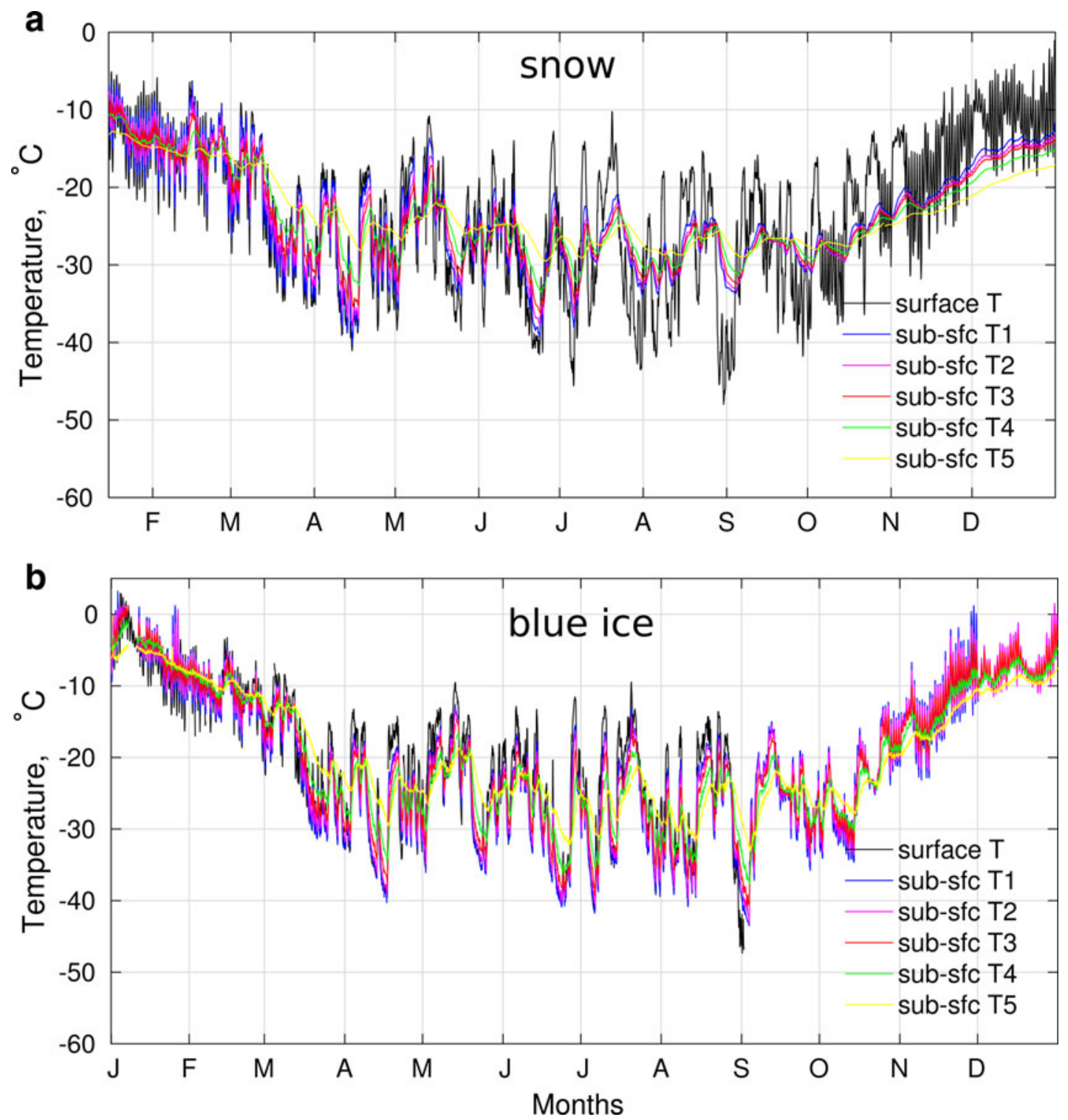

Fig. 8. Two hourly mean temperatures for two sites during 1998: AWS6 located on a snow surface (a) and AWS7 located on a blue ice surface (b). Surface temperature is calculated using outgoing and incoming longwave radiation fluxes. Temperatures are measured initially at depths $5 \mathrm{~cm}$ (T1), $10 \mathrm{~cm}$ (T2), $20 \mathrm{~cm}$ (T3), $40 \mathrm{~cm}$ (T4) and $80 \mathrm{~cm}$ (T5). The actual depth varies depending on accumulation/ablation on snow/ice surface. 

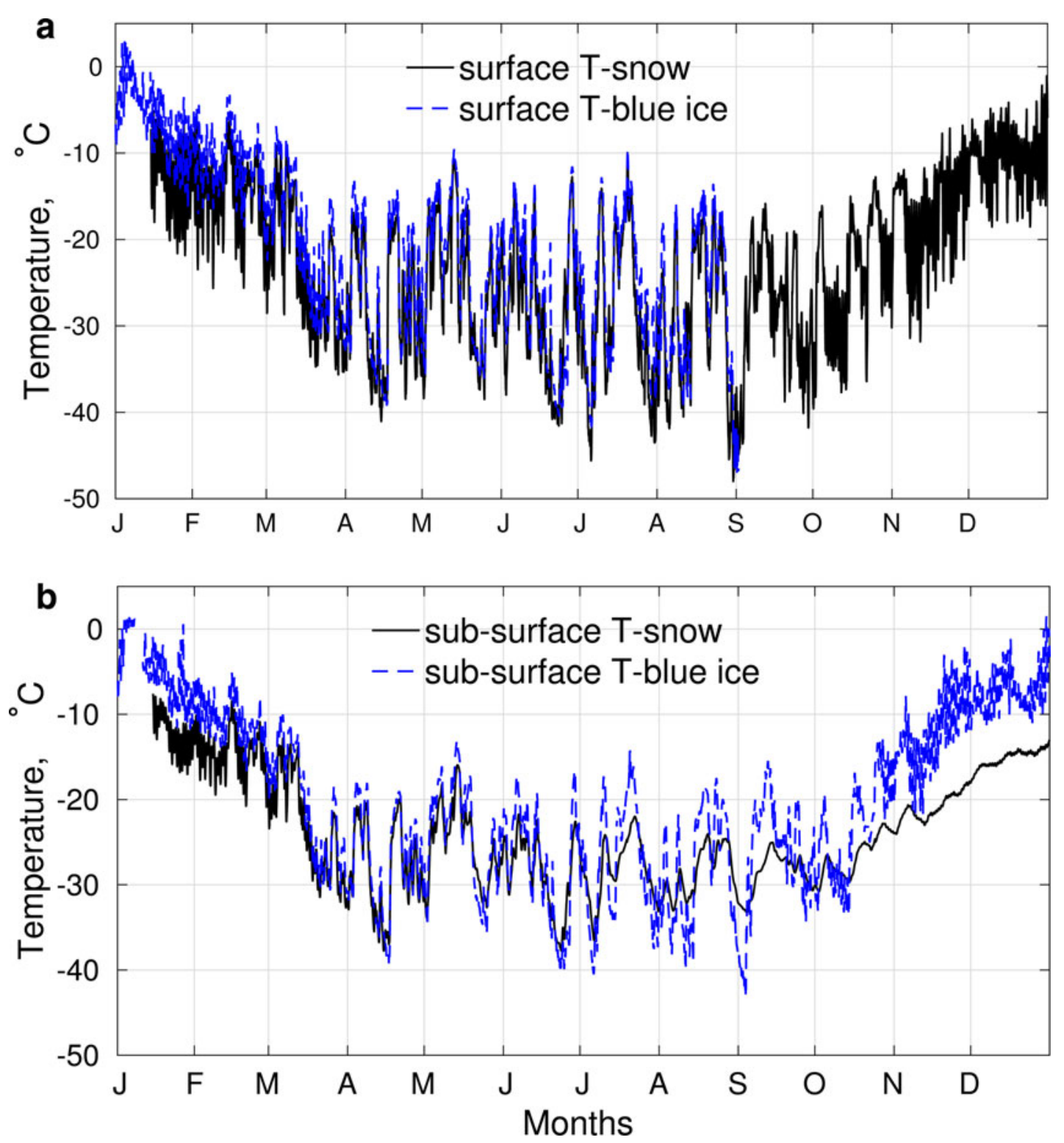

Fig. 9. Two hourly mean temperatures comparison at two sites for surface temperatures (a) and subsurface temperatures initially at $10 \mathrm{~cm}$ (T2) below the snow/ice surface (b). Black solid line is for snow site and blue dashed line is for blue ice site. The actual depth varies depending on accumulation/ablation on snow/ice surface. The dataset of the surface ice blue temperatures (blue dashed line in (a)) stopped on 02 September 1998.

temperature variability but rather with long periods of surface cooling with temperature below $-30{ }^{\circ} \mathrm{C}$. The analysis of Svea measurements shows that both blue ice and snow surface temperatures are comparable and for temperatures below $-30{ }^{\circ} \mathrm{C} \mathrm{BIAs}$ are on average warmer only by $1.05{ }^{\circ} \mathrm{C}$.

Large daily variability in summer and strong cooling during the winter of subsurface temperatures are important for the thermal stress causing icequakes. The daily variability in subsurface temperatures reduces with depth compared to the surface temperatures (Fig. 8). Snow site experiences snow accumulation during the year, while ablation dominates the blue ice site. Thus, the subsurface temperatures installed at the same initial depth at the snow site show smaller daily variability later during the year compared to the blue ice site. Figure 9 shows a comparison between surface temperatures and subsurface temperature initially at $10 \mathrm{~cm}$ depth at the two sites. The subsurface temperature at the blue ice site is warmer compared to the snow site with the daily amplitude $2{ }^{\circ} \mathrm{C}$ larger compared to the subsurface temperature at the snow site (mean diurnal variability during summer months is on average $4{ }^{\circ} \mathrm{C}$ at the snow site and $6{ }^{\circ} \mathrm{C}$ at the blue ice site). During winter the minimum subsurface temperatures at the blue ice site are somewhat colder (on average by $2{ }^{\circ} \mathrm{C}$ ). As the blue ice site is dominated by ablation, this explains stronger cooling of subsurface temperatures in winter compared to the snow site characterized by accumulation. This comparison of the surface and subsurface temperature behavior at the snow and blue ice sites supports the conclusions of the paper based on the AWS at the snow site. 